\title{
PAISAJES (NEO)GÓTICOS EN LA NOVELA LOS SUSURROS DE PERSEO DE JOSÉ RICARDO CHAVES
}

Karen Poe Lang

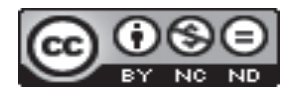

Esta obra está bajo una licencia Creative Commons Reconocimiento-No Comercial-Sin Obra Derivada 



\title{
PAISAJES (NEO)GÓTICOS EN LA NOVELA LOS SUSURROS DE PERSEO DE JOSÉ RICARDO CHAVES
}

\author{
(NEO)GOTHIC LANDSCAPES IN THE NOVEL LOS SUSURROS DE \\ PERSEO BY JOSÉ RICARDO CHAVES
}

Karen Poe Lang

\begin{abstract}
RESUMEN
El propósito de este artículo es analizar los elementos (neo)góticos en las formas de representación del paisaje, en la novela Los sussurros de Perseo del escritor costarricense José Ricardo Chaves. A partir de ejemplos concretos, intentaré demostrar cómo algunos rasgos góticos en la representación del paisaje son resignificados y tratados desde una distancia irónica. El paisaje se utiliza de manera crítica para poner en evidencia problemas de gran vigencia como la xenofobia o la homofobia.

Palabras clave: literatura costarricense, paisaje, literatura (neo)gótica, Chaves-José Ricardo, Los susurros de Perseo.
\end{abstract}

\begin{abstract}
The purpose of this article is to analyze (neo)gothic elements in the representation of landscape in the novel Los susurros de Perseo, by Costarrican writer José Ricardo Chaves. Based on textual examples, I will try to demonstrate how some (neo)gothic features in the representation of landscape are resignified and treated from an ironical distance. Landscape is used to criticize very important problems as xenophobia and homophobia.

Key words: Costarrican literature, landscape, (neo)gothic literature, Chaves-José Ricardo, Los susurros de Perseo.
\end{abstract}

\section{Introducción}

Desde sus inicios, la obra narrativa del escritor costarricense -radicado en MéxicoJosé Ricardo Chaves ha mostrado un gran interés por la literatura fantástica, especialmente en su vertiente gótica, como se explicita en algunos de los títulos de sus libros de relatos: Cuentos tropigóticos (1997, Premio Aquileo Echeverría) y Jaguares góticos (2003). También, su obra ensayística ha estado dedicada ampliamente al estudio de la literatura fantástica dentro

Dra. Karen Poe Lang. Universidad de Costa Rica. Profesora Catedrática. Escuela de Estudios Generales. Coordinadora de la Maestría en Artes con Énfasis en Cinematografía. Costa Rica.

Correo electrónico: k.poe.lang@gmail.com

Recepción: 21- 11- 2013

Aceptación: 15- 03- 2014 
de la cual es posible destacar algunos títulos: Andróginos. Eros y ocultismo en la literatura romántica (2005) y sus dos antologías El castillo de lo inconsciente. Antología de literatura fantástica de Amado Nervo (2000) y Voces de la sirena. Antología de literatura fantástica de Costa Rica (2012). Esta doble inclinación (teórica y narrativa) por la literatura fantástica hacen de la escritura de Chaves un espacio idóneo para estudiar las marcas de este género literario en una narrativa contemporánea.

El propósito de este trabajo es analizar las representaciones (neo)góticas del paisaje en su novela Los susurros de Perseo (2008 [1994], finalista del Premio Herralde). A partir de ejemplos concretos, intentaré demostrar cómo algunos rasgos góticos en la representación del paisaje son resignificados y tratados desde una distancia irónica. El paisaje es así un elemento que refleja los estados de ánimo de personajes o grupos humanos y, a la vez, se utiliza de manera crítica para poner en evidencia problemas de gran vigencia como la xenofobia o la homofobia. Especial atención merece el manejo casi cinematográfico de la luz, la bruma y la niebla como marcas discursivas de la culpa y la exclusión social.

\section{Los susurros de Perseo}

San José es un alfabeto al que le faltan letras, y por eso se oye tan triste, monótona, desmemoriada. Es la literatura urbana lo único que permite que siga existiendo, el único vínculo de la memoria y la gente con esta mole de concreto y asfalto.

(Contreras, 2013, párr. 1)

Los susurros de Perseo es un texto que parodia la novela de formación (bildungsroman) que se centra en el despertar sexual de sus tres protagonistas adolescentes: Luciano, Andrade y Renato. A pesar de que buena parte de la acción transcurre en el espacio cerrado de un colegio católico, los valores tradicionales de la novela de formación son subvertidos de tal forma que la experimentación de diversas tendencias eróticas (generalmente consideradas perversas por la moral dominante) no es jamás juzgada por la mirada del narrador. En este sentido, la novela hace gala de un profundo amoralismo que se puede asociar con el decadentismo finisecular europeo e hispanoamericano. Aunque no es tema de este ensayo, cabe destacar que desde el punto de vista del estilo la novela está escrita como si se tratara de un texto modernista hispanoamericano.

Además, Los susurros de Perseo es un texto polifónico y fragmentario, dividido en veinte capítulos que, a partir de sus títulos sugerentes, deconstruyen lúdicamente otros textos del canon literario. Así "En el jardín de los amores que se bifurcan" o "Premio de una noche de verano" pueden ser leídos como relatos unitarios y al mismo tiempo como capítulos de la novela, que a pesar de su marcada tendencia centrífuga, mantiene una línea argumental. En esta narración, Chaves retoma y desarrolla, con particular cuidado, temas que ya había tratado en su primer libro de cuentos La mujer oculta (1984) $)^{1}$ como por ejemplo la ambigüedad sexual, el homoerotismo y los problemas de identidad que acosan a las minorías sexuales.

Los críticos como Cortés (2008) y Valencia (2003), quienes se han dado a la tarea de estudiar la obra de Chaves, coinciden en destacar la ausencia de textos que analicen a fondo su obra narrativa a pesar de su gran calidad y de la vigencia de sus planteamientos. Esta situación ha comenzado a cambiar en los últimos años, en los cuales la obra de Chaves ha despertado un gran interés en el ámbito académico universitario ${ }^{2}$. Para Valencia, La mujer oculta: 
[...] puede ser considerado como un documento de denuncia de las demarcaciones genéricas (sexuales) asignadas y del fenómeno de la homofobia internalizada como producto de estas y sus manifestaciones de poder, abuso y violencia. La obra proporciona ejemplos tangibles de devastadoras y múltiples consecuencias y de cómo estas no sólo afectan a la persona que se enfrenta al dilema de la identidad sexual, sino el medio social que la rodea. Por otro lado, pone en evidencia y cuestiona el falocentrismo de la sociedad patriarcal costarricense y lo acusa implícitamente de ser la fuente de muchos de los elementos marginalizantes que se manifiestan en contra de los derechos y de las identidades individuales. (Valencia, 2003, p. 67)

Los susurros de Perseo aúna a este carácter de denuncia del falocentrismo y la sociedad patriarcal el problema de la xenofobia, ya que el personaje de Renato, además de ser homosexual es extranjero, condiciones que lo sitúan inevitablemente en el papel de víctima. A pesar de que el texto nunca indica explícitamente el nombre del lugar dónde ocurren los hechos, existen claves para que el lector identifique el valle central y la capital con la ciudad de San José. La descripción del paisaje y de un aguacero tropical son marcas textuales inconfundibles, al menos para un costarricense.

Como propone López-Santos:

El espacio, como sabemos, es el elemento estructural cuya finalidad no se reduce a ser el ámbito en el que se desarrolla la acción, sino que ayuda a configurar los rasgos psicológicos de los personajes e influye en sus conductas, llegando a erigirse, en algunos casos, en el verdadero eje determinante y definitorio de la obra literaria. Este es el caso del relato gótico al que el espacio ha servido de base constitutiva. (2010, p. 6)

Además de la recreación de algunos personajes arquetípicos, como el vampiro o el cura perverso, uno de los principales rasgos góticos de Los susurros de Perseo es precisamente la importancia estructural que cobra el paisaje como indicador de la psicología de los personajes y como pivote y motor de la acción narrada. La descripción detallada de la ciudad, de los cambios climáticos, del bosque, del valle central y de algunos de sus edificios emblemáticos es mucho más que un simple decorado y en algunos pasajes estos elementos se convierten en personajes sin los cuales la trama no podría avanzar.

Al no existir en Costa Rica castillos ni grandes conventos, que han sido tradicionalmente los espacios preferidos por la literatura gótica, el burdel, el colegio y las viejas casonas abandonadas se convierten en las marcas geográficas que determinan el curso del deambular nocturno de sus personajes adolescentes. Un rasgo notable de los paisajes de Chaves (2008) es que, además de reflejar el estado de ánimo de uno o varios personajes, son esencialmente territorios transitables. El paisaje se convierte así en algo que hay que atravesar, a pie y de noche, pues los protagonistas de la novela son esencialmente caminantes, paseantes o flanneurs, que se desplazan por la geografía urbana que está, sin embargo, signada por espacios naturales como bosques o parques. En este sentido, se puede afirmar que el paisaje en Los susurros de Perseo no está hecho para ser contemplado sino para ser vivido desde adentro.

Particular importancia adquiere la descripción del histórico burdel La Maison Doreé, que en el texto recibe también el nombre de La casa de Bernarda Calva, en honor al mágico travesti que lo regenta. El burdel, que verdaderamente existió en San José, es un lugar central en la trama, ya que ahí se comete una violación incestuosa y termina consumido por las llamas en las cuales arden sus dueños. Una noche, Momo (un personaje secundario) va en busca de Rómulo, su padre y dueño del prostíbulo, a quien no conoce pues su madre se ha negado durante años a develarle el nombre. Las características del lugar terminan por hacerlo desistir de su propósito: 
Durante varias noches Momo rondó, como una sombra delincuente, la mansión indicada por Justina. Evidentemente se trataba de una casa bastante concurrida. En esto no residía el enigma. Tenuemente iluminada, en ciertos rincones las penumbras conformaban escenarios tenebrosos, siniestros altillos dignos de la prosa de Lovecraft. Los altos pinos en nada alegraban la vista, sino que más bien contribuían a un escenario de lobreguez. Todo ello generaba una atmósfera bizarra, sobre todo por el triste candor que inspiraban las estatuas que simulaban faunos musicantes, pródigas cornucopias, hasta un remedo del David de Miguel Ángel. (Chaves, 2008, p. 123)

Una iluminación discreta, pero lo suficientemente capaz de despertar susceptibilidades sensuales en los transeúntes, era otro elemento de la remodelación, de aquella serie de cambios que apenas se inciaba en la Maison Dorée de Rómulo y Bernarda. Hasta ahora lo logrado se sintetizaba en una amorfa decadencia. (Chaves, 2008, p. 124)

Cabe resaltar un aspecto importante de esta descripción, en la cual a los rasgos tradicionales del paisaje gótico como la penumbra, lo siniestro, la decadencia y la lobreguez, se aúna el elemento kitsch de las estatuas neoclásicas, que en cierto modo desbarata el efecto maligno y atemorizante del lupanar. Es por esta razón que considero pertinente calificar el paisaje como (neo)gótico, ya que la mirada del narrador, debido a su caractér irónico, produce un efecto distanciador.

Por razones de espacio, no puedo abarcar toda la riqueza que propone la novela en la representación del paisaje, por lo que me centraré en dos capítulos particularmente importantes: "El gato blanco" y "Azul" que es la última sección con la cual finaliza la novela. Además, no trataré toda la riqueza y amplitud de las relaciones entre los personajes, sino que focalizo mi atención en el paisaje que circunda el vínculo homoerótico que une a Renato y Andrade. ${ }^{3}$

\section{El gato blanco}

Por mi parte, pronto sentí nacer en mí una antipatía hacia aquel
animal. Era exactamente lo contrario de lo que había anticipado,
pero -sin saber cómo ni por qué- su marcado cariño por mí me
disgutaba y me fatigaba. Gradualmente, el sentimiento de
disgusto y fatiga creció hasta alcanzar la amargura del odio. (Poe, 2012, p. 206)

El gato blanco -que corresponde al capítulo once de la novela- es una clara referencia intertextual al cuento de Poe. En este, se narra un encuentro siniestro entre Andrade y un viejo hombre/gato. Esta sección de la novela transcurre en dos locaciones: primero en un parque y luego en una casona abandonada:

El parque que tanto visitaba Andrade no dejaba de tener un aspecto siniestro. Apenas una que otra luz que insinuaba claroscuros, sombras sinuosas, tupidos arbustos a cuya penumbra se suscitaban repetitivos juegos afrodisios. [...] En ese lugar de sexo libre concurría todo tipo de hombres en las horas obscuras, desde sofisticados dandis del abismo hasta ladrones lascivos y engañosos criminales. Así, no era extraño que cada cierto tiempo, al amanecer, se descubriera el cadáver de alguien que buscando gozo encontró la muerte. (Chaves, 2008, p. 139)

Unas líneas más adelante, el narrador relata que en una ocasión habían violado y matado a una prostituta, quien convertida en fantasma seguía ejerciendo el oficio. Cuentan que sólo después de la muerte de siete de sus clientes a causa de una enfermedad desconocida, (siete era también el número de violadores) el fantasma pudo descansar y abandonar el siniestro lugar.

Andrade, quien con anterioridad ha sido comparado con un vampiro, mantiene dos relaciones sexuales al mismo tiempo. Además de su relación con Renato, su compañero de colegio, frecuenta la cama de Bruria, una mujer mayor amiga de su madre. Profundamente 
alterado por los celos, Renato se presenta un buen día en casa de Bruria y arma un escándalo. A partir de ese momento, Andrade (quien no le perdona el bochorno) aprovecha la menor ocasión para humillar a Renato en público. Como el personaje del cuento de Poe respecto del cariño de su gato, Andrade siente desprecio por el amor y la entrega incondicional de Renato.

Un día, Andrade deambula por el parque y se encuentra con un viejo que fuma pipa y lee el periódico, quien captura su atención a tal punto que lo sigue por un callejón hasta una vieja casona abandonada.

\footnotetext{
El viejo se detuvo ante una enorme puerta de madera, carcomida, golpeada, pero victoriosa, que daba acceso al patio de una vieja casona no menos lastimada, no menos quejumbrosa. Antes de empujar la puerta, el anciano miró en dirección de Andrade. El joven observó la mirada amarilla y la irregularidad de una oreja que carecía de lóbulo. Después el viejo cruzó el umbral.

Luego de esperar un rato, Andrade decidió entrar. Había caminado alrededor de la casona deteriorada. $\mathrm{Su}$ aspecto causaba una segura sensación de abandono, de antro habitado por toda suerte de espectros y recuerdos pululantes.

No hubo chirridos de puerta (esta narración no es de estilo gótico. Quien escribe esto no pretende imitar a Walpole o a Stoker). La puerta daba a un patio previsiblemente abandonado, logrando así lógica armonía con la descripción hecha antes. (Chaves, 2008,pp. 143-144)
}

Nuevamente cabe destacar la intervención lúdica del narrador, que establece una distancia y a la vez acerca su relato hacia el estilo de la descripción y el espacio gótico, que como ha indicado López-Santos (2010, p. 277) "más que un espacio referencial, es un espacio estético". La mención de Walpole y Stoker ubica el texto en una clara filiación literaria.

El narrador nos cuenta que Andrade logra entrar a una habitación mezcla de humedad, mal olor (por la caca de gato) y deterioro. Sin embargo, el muchacho se sentía en una especie de rapto o trance hipnótico que le impedía abandonarla. La casa estaba totalmente llena de gatos que parecían obedecer a un enorme gato blanco. Andrade descubre con terror, que el animal tiene el mismo defecto en el lóbulo de la oreja, que unos minutos antes, había observado en el viejo, a quien no encuentra por ninguna parte.

\footnotetext{
No pudiéndose explicar el paralelismo, Andrade sintió un escalofrío que le surcó la espalda. Un terror de sinrazón, de incoherencia, hizo presa de él, haciendo nacer en el muchacho un único deseo: salir de ahí lo más pronto posible. [...] Andrade comenzó a correr rumbo a la puerta, mientras los gatos no cesaban de mirarlo. Apenas hubo cruzado el umbral, chirriantes maullidos estallaron en el aire, no en coro, no al unísono, sino caóticos y dispersos. (Chaves, 2008, p. 147)
}

Andrade es un gran consumidor de droga por lo que durante todo el capítulo el lector tiene la duda de que los hechos narrados sean reales o un efecto alucinatorio de la ingestión de una sustancia alucinógena. Este es uno de los aspectos claramente fantásticos de toda la novela, cuya estructura narrativa se basa en buena parte en sueños, pesadillas y alucinaciones. Como ha indicado Zavala (2011, párr. 3), en la literatura fantástica: "El logocentrismo del progreso de la ciencia y la industria se invierten mediante las indecibilidades, las naturalezas inexplicables y monstruosas, lo considerado irracional, el sueño, las pesadillas".

En este sentido, se puede afirmar que el capítulo "El gato blanco" funciona como una especie de presentación del personaje de Andrade, como una indagación onírica de los aspectos irracionales de su personalidad y, en cierta forma, también es una representación metafórica de su "maldad". Aunque la novela no es maniqueista ni juzga a sus personajes, es imposible obviar que Andrade se porta tan mal con su amigo y compañero sexual y lo humilla a tal extremo que lo conduce al suicidio. De este modo, la novela trata uno de los grandes temas de la literatura gótica ya que según Zavala: 
La corriente gótica explora el lugar y el origen del mal en la naturaleza humana y la ferocidad del deseo en los ojos. Es, en definitiva, un género cognitivo con significación política, con un repertorio de elementos temáticos y especificidades formales, que se van transformando. (2011, párr. 6)

En la novela de Chaves (2008), el recurso al género fantástico y al estilo gótico son puestos al servicio de una posición ideológica y de un planteamiento político claros. Se trata de denunciar de un modo creativo y nada panfletario la homofobia generalizada, pero sobre todo, la internalizada, la que carcome las entrañas de Andrade, como el gato negro lapidado junto al cadáver de la mujer en la pared del cuento de Poe. La turbia personalidad de Andrade, su desprecio y sobre todo su odio por Renato, su leal y sumiso compañero sexual, carecen de explicación lógica y son representados desde un universo fantástico de estilo gótico que como ha indicado Sagot:

El gótico introduce en el alma humana una terrible sospecha: no somos tan racionales, tan lúcidos, tan transparentes, tan cientificistas como lo suponemos. Nos habitan fuerzas oscuras e innombrables. Reconocer el elemento irracional en la psique humana -y darle forma artística- es el mayor mérito de la literatura gótica. (Sagot citado en Calvo-Díaz, 2013, p. 38)

\section{Azul}

Luciano, Andrade y Renato son estudiantes de último año de bachillerato en un colegio de clase alta de la capital. El día del estudiante terminal es un espacio-tiempo carnavalesco, en el cual se relajan las normas y costumbres. Los alumnos mayores pueden aprovecharse de los menores en este día que es también una despedida. A pesar de que Renato es estudiante terminal, Andrade se aprovecha de su condición de extranjero para humillarlo, con la complicidad de sus compañeros.

\footnotetext{
Andrade dio rienda suelta a su rabia casi siempre controlada y se lanzó sobre Renato, a quien arrastró hacia un árbol en uno de los patios y, con ayuda de otros terminales, lo desnudó y, con cinturones, lo amarró al tronco. Renato, furibundo, gritaba improperios y, ante las acusaciones de traidor que argüía Luciano, Andrade alegaba la condición de extranjero del amarrado, lo que introducía una modificación en el trato. Además, él fue el que lo arrastró hasta el árbol y los otros sólo lo ayudaron a atarlo con los cinturones. (Chaves, 2008, p. 240)
}

La desproporcianada humillación de Renato amarrado al árbol, sobre cuya cabeza orinan sus compañeros alentados por Andrade, culmina con su lanzamiento a la piscina, de la cual es rescatado por Luciano, quien sabía que su amigo no era capaz de nadar. Casi ahogado, Renato logra sobrevivir, pero esa misma noche se suicida, arrojándose en la misma alberca. Es encontrado a la mañana siguiente por el director del colegio quien se maravilla ante el contraste del pelo rojo del muchacho y el color azul de su piel. A partir de entonces, nos dice el texto, el padre Fabio asoció siempre el color azul con la muerte, la decadencia y la melancolía. Este color azul, de ahora en adelante vinculado con la muerte, se apodera lentamente de todo el valle central, como un signo siniestro y acusador, como emblema de la culpa colectiva por la muerte del joven. La ciudad dormida, despierta cubierta de una bruma que la enfrenta a su propia hipocresía, a su homofobia soterrada, a su xenofobia contra los seres desprotegidos y diferentes.

Un día el clima amaneció sumamente frío, más de lo habitual para esa época del año. Lo más llamativo fue la bruma azulosa que, durante la noche, había invadido el valle. Una neblina que, sin ser muy densa, sí era extensa. Al principio fue una curiosa novedad que todo el mundo comentaba, los vecinos, los burócratas en sus escritorios, los médicos a los enfermos, los noticieros de televisión y radio, los periódicos y la bruma azul era el fenómeno del día, la bruma y el frío y la gente se abrigaba como nunca lo había hecho [...]. (Chaves, 2008, p. 253) 
La bruma y el azul constituyen un paisaje en el cual el color es más importante que el contorno y la claridad del dibujo. No olvidemos que esto era precisamente lo que defendían Baudelaire en sus Salones y los pintores románticos. En Los susurros de Perseo, el color, debido a sus posibilidades expresivas y emotivas, se privilegia sobre la línea y el dibujo para representar un espacio en el cual el azul simboliza el frío propio del cadáver y por lo tanto de la muerte. El color azul, convertido en personaje, avanza sobre el valle central y va destruyendo lo que encuentra a su paso, sobre todo a los seres más débiles. Es así como el color azul viaja por las páginas de la novela y salta desde la piel azulada del cuerpo muerto de Renato para propagarse como un virus y se desplaza hasta cubrir todo el espacio físico y espiritual de la ciudad.

\footnotetext{
La bruma se había adueñado del valle central, de la capital; algunos hombres, plantas y árboles murieron; los pobres en las barriadas se enfermaban de gripe y pulmonía, aumentaba el ausentismo laboral, las iglesias no daban abasto con los fieles y sus misas de fin de mundo; en síntesis, un gran problema social que el gobierno no podía resolver: la bruma no se iba. El azul todo lo invadía.

[...] según los estudios, la bruma en sí misma no era dañina, no tenía ningún componente letal; el problema radicaba en el frío y en la falta de luz, con sus consecuencias psicológicas: el desamparo, la tristeza. (Chaves, 2008, p. 254)
}

Esta tristeza colectiva es también sentida de forma individual por Luciano, quien ante la dolorosa muerte de su amigo, sufre de culpa por no haber sido capaz de salvarlo. El texto utiliza el recurso de la sinestesia para dar vida a la bruma y al color azul que ya no son percibidos por la vista sino que, además de metaforizar la interioridad convulsa y sin rumbo de su personaje, son experimentados literalmente en el cuerpo y en el espíritu. De ese modo, la bruma y el color azul producen un estado de confusión tal que el protagonista no sabe distinguir entre el sueño y la vigilia, la noche y el día.

\footnotetext{
Las primeras veces que Luciano caminó entre la niebla se sintió perdido. A decir verdad, la coloración azul creaba una atmósfera particular; los rosales y los árboles brillaban casi fosforescentemente y a ratos tenía la sensación de estar despierto en un sueño. Si no fuera por el reloj, Luciano no sabría si lo que experimentaba era el alba o el ocaso, el amanecer o el crepúsculo: esos matices azulados, grises, metálicos, bien podían ser de nacimiento o de muerte. (Chaves, 2008, p. 254)
}

El final de la novela, de un marcado tono distópico, es además ominoso si partimos de una de las definiciones dadas por Freud (1979, p. 221) a ese término, como "algo dentro de lo cual uno no se orienta". De este modo, el texto hace coincidir el sentimiento de lo ominoso en dos planos, el individual y el colectivo como metáfora de la culpa por la muerte de un joven inocente, víctima de la homofobia y la xenofobia. Ambiente ominoso que atrapa también al lector quien termina desorientado y perdido en el paisaje de palabras del texto.

\section{Notas}

1. Este libro recibió el Premio Joven Creación en la rama de cuento, otorgado por la Editorial Costa Rica.

2. En este panorama cabe destacar dos trabajos: Calvo-Díaz, K. (2013). La literatura gótica en Costa Rica: El discurso de lo subversivo a partir de la narrativa breve de José Ricardo Chaves. (Tesis de Maestría en Literatura Latinoamericana). Universidad de Costa Rica, y Coto-Rivel, S. (2007). Espacios de marginalidad y nuevas propuestas de género: La construcción del discurso homoerótico en la novela Paisaje con tumbas pintadas de rosa de José Ricardo Cháves. (Tesis de Maestría Académica en Literatura Latinoamericana). Universidad de Costa Rica.

3. Un tema fundamental que cruza toda la novela y la acerca a la literatura fantástica es el del andrógino. He estudiado este aspecto del texto en Poe-Lang, K. (2013). Metáforas del cuerpo ambiguo. Una lectura de Los susurros de Perseo y Arias de don Giovanni. En Poéticas y políticas de género. Ensayos sobre imaginarios, literaturas y medios en Centroamérica. (159-186). Berlín: Editorial Tranvía-Walter Frey. 


\section{Bibliografía}

Calvo-Díaz, K. (2013). La literatura gótica en Costa Rica: El discurso de lo subversivo a partir de la narrativa breve de José Ricardo Chaves. (Tesis de Maestría en Literatura Latinoamericana). Universidad de Costa Rica.

Chaves, J.R. (1984). La mujer oculta. San José: Editorial Costa Rica.

Chaves, J.R. (1997). Cuentos tropigóticos. México: Universidad Nacional Antónoma de México.

Chaves, J.R. (2000). El castillo de lo inconsciente. Antología de literatura fantástica de Amado Nervo. México: Conaculta.

Chaves, J.R. (2003). Jaguares góticos. México: El umbral.

Chaves, J.R. (2005). Andróginos. Eros y ocultismo en la literatura romántica. México: Universidad Nacional Autónoma de México.

Chaves, J.R. (2008 [1994]). Los susurros de Perseo. San José: Uruk.

Chaves, J.R. (2012). Voces de la sirena. Antología de literatura fantástica de Costa Rica. San José: Uruk Editores.

Contreras, F. (2013, 8 de enero). Fernando Contreras: el peor gato callejero. [Entrevista con Randall Zúñiga]. Revista Su Casa. http://www.revistasucasa.com/ [Consulta 24 de mayo de 2013].

Cortés, C. (2008). Prólogo. Por J.R. Chaves. Los susurros de Perseo. San José: Uruk.

Coto-Rivel, S. (2007). Espacios de marginalidad y nuevas propuestas de género: La construcción del discurso homoerótico en la novela Paisaje con tumbas pintadas de rosa de José Ricardo Chaves. (Tesis de Maestría en Literatura Latinoamericana). Universidad de Costa Rica.

Freud, S. (1979). Lo ominoso. Por J. Strachey y A. Freud (Comps.) y J. Etcheverry (tr.). Obras completas. (Vol. 17, 215-251). Buenos Aires: Amorrortu. (Trabajo original publicado en 1919).

López-Santos, M. (2010). Ampliación de los horizontes cronotópicos de la novela gótica. Signa. (19), 273-292.

Poe, E.A. (2012). El gato negro. En Obras Selectas. (203-210). Madrid: Edimat Libros.

Poe-Lang, K. (2013). Metáforas del cuerpo ambiguo. Una lectura de Los susurros de Perseo y Arias de don Giovanni. Por A. Ortiz-Wallner y M. Albizúrez-Gil (Eds.). Poéticas y políticas de género. Ensayos sobre imaginarios, literaturas y medios en Centroamérica. (159-186). Berlín: Editorial Tranvía-Walter Frey.

Sagot, J. (2013). Entrevista. Por Calvo-Díaz, K. La literatura gótica en Costa Rica: El discurso de lo subversivo a partir de la narrativa breve de José Ricardo Chaves. (383-389). (Tesis de Maestría en Literatura Latinoamericana). Universidad de Costa Rica.

Valencia, J. (2003). Género, homofobia interiorizada y falocentrismo en La mujer oculta de José R. Chaves. Letras. (35), 65-79.

Zavala, I.M. (2011). Erotismo y terror: el fantasma del texto o cuando los espejos tienen manchas. Biblioteca Virtual Miguel de Cervantes. http://www.cervantesvirtual.com/ [Consulta 23 de abril de 2013]. 